Board of Governors of the Federal Reserve System

International Finance Discussion Papers

Number 690

December 2000

\title{
NEWS AND NOISE IN G-7 GDP ANNOUNCEMENTS
}

\author{
Jon Faust, John H. Rogers, and Jonathan H. Wright
}

NOTE: International Finance Discussion Papers are preliminary materials circulated to stimulate discussion and critical comment. References to International Finance Discussion Papers (other than an acknowledgment that the writer has had access to unpublished material) should be cleared with the author or authors. Recent IFDPs are available on the Web at www.federalreserve.gov. 


\title{
NEWS AND NOISE IN G-7 GDP ANNOUNCEMENTS
}

\author{
Jon Faust, John H. Rogers, and Jonathan H. Wright*
}

\begin{abstract}
Revisions to GDP announcements are known to be quite large in all G-7 countries: many revisions in quarterly GDP growth are over a full percentage point at an annualized rate. In this paper, we examine the predictability of these data revisions. Previous work suggests that U.S. GDP revisions are largely unpredictable, as would be the case if the revisions reflect news not available at the time that the preliminary number is produced. We find that the degree of predictability varies throughout the G-7. For the U.S., the revisions are very slightly predictable, but for Italy, Japan and the UK, about half the variability of subsequent revisions can be accounted for by information available at the time of the preliminary announcement. For these countries, it appears that revisions reflect, to a significant degree, the removal of noise from the preliminary numbers, rather than the arrival of news.
\end{abstract}

Keywords: Vintage data, preliminary data, final data, revision, GDP.

* Division of International Finance, Board of Governors of the Federal Reserve System. We thank for useful comments Dean Croushore, Joe Gagnon, Jane Haltmaier, David Howard, Jane Ihrig, Andrew Levin, Athanasios Orphanides, Matthew Shapiro, and Charles Thomas. Thanks to Anthony Leegwater, David Kobuszewki, and Lisa Workman for excellent research assistance. The views in this paper are solely the responsibility of the authors and should not be interpreted as reflecting the views of the Board of Governors of the Federal Reserve System or of other members of its staff. 


\section{Introduction}

Macroeconomic data are often subject to large revisions after initial release and for many data series, the data revision process continues essentially indefinitely. The inaccuracy of initial data obviously complicates decision making by policymakers and other agents whose optimal choices depend on the state of the economy. Several authors have recently emphasized that the revision process also complicates the ex post analysis of macro data. Macroeconometric work is generally based on the most fully revised available data (ignoring any earlier data vintages). The conclusions of such work rest on the implicit assumption that at each point in time, agents perfectly predict future data revisions. This assumption is particularly curious given the fact that revisions should be completely unpredictable if the statistical agency is efficiently processing available information.

Studies of the revision process in U.S. GDP data show that unpredictability or weak predictability of revisions is a better assumption than perfect predictability (e.g., Mankiw and Shapiro, 1986). Further, macroeconometric work based on real-time data often yields substantively different conclusions from work ignoring revisions (see, for example, Diebold and Rudebusch (1991), Robertson and Tallman (1998), Evans (1998), Orphanides (1998, 2000) and Croushore and Stark (1999)).

In this paper, we study the predictability of revisions to GDP announcements for the G-7 countries. We extend earlier work both by including a broader range of economies and by taking a longer sample of data - at longest 1965-1997. As with the earlier work, the primary tools we use are statistical tests of whether the preliminary announcement is a rational forecast of the subsequently revised data.

We find some evidence of predictability of revisions for each country we consider. For several countries - the UK, Italy, and Japan - the revisions are highly predictable: about half the variance of revisions can be accounted for by information available at the time of the initial announcement. Preliminary announcements in some countries are biased. The variable with the most power to predict future revisions to GDP is the preliminary GDP announcement itself- extreme prelimi- 
nary announcements tend to be revised toward the mean. We consider seasonal dummy variables and 5 other predictors that are publicly known at the time of the preliminary announcement: the lagged preliminary announcement, an equity index, short-term interest rates, oil prices, and a dummy variable for national elections. While each of these variables has predictive power in at least one country, in no case do these additional variables make major contributions to the overall predictive power. Most notable among these results for additional predictors is the fact that in the Japanese data, the last GDP growth rate announced before national elections is systematically about one percentage point (at an annual rate) more optimistic than in other quarters. This result is robust for Japan, but the election effect is not found in any other country. We discuss possible sources and implications of all these results in the final section.

The plan of the remainder of this paper is as follows. Section 2 reviews standard models of the revision process, the role of efficient forecasts and forecast tests. Section 3 describes our dataset. Sections 4 and 5 present baseline results and extensions, and the final section provides some interpretation of the results.

\section{Revisions, News, Noise, and Efficient Predictions}

The revision process is characterized by two polar cases labelled news and noise by Mankiw, Runkle, and Shapiro (1984) and Mankiw and Shapiro (1986). Under the noise view, the preliminary GDP data are polluted with measurement error, noise, that is uncorrelated with the true values. The preliminary GDP number will not be an optimal estimate of GDP in this case, and agents face a filtering problem in forming their optimal estimate. Various approaches to this filtering problem have been proposed (Howrey, 1978, 1984; De Jong, 1987; and Mariano and Tanizaki, 1995).

Under the news characterization, the statistical agency optimally uses all available information in forming the preliminary number, and revisions must reflect news that arrives after the announcement. The news view will be appropriate so long as 
the statistical bureau is choosing the preliminary number to minimize any one of a number of standard loss functions that are symmetric and increasing in the size of revisions. Some national statistical offices explictly discuss minimizing revisions as a goal of their processes, and most presumably include this among the desiderata in data construction. ${ }^{1}$

When revisions are minimized, the preliminary number will be what is known as a rational, efficient, or optimal forecast of the subsequently revised data. The revision will be orthogonal to information available when it is produced. More formally, under both the news and noise views, we can characterize the preliminary data as equal to the final plus an error term:

$$
X_{t}^{p}=X_{t}^{f}+\varepsilon_{t}
$$

Under the noise view, $\varepsilon_{t}$ is orthogonal to $X_{t}^{f}$, while in the news view, $\varepsilon_{t}$ is orthogonal to $X_{t}^{p}$. Obviously, there are intermediate cases in which $\varepsilon_{t}$ is correlated with both preliminary and final data.

Predictability of revisions can arise in fairly innocuous ways. Suppose output data are available before income and expenditure data so that the preliminary announcement gives GDP measured on an output basis only. The final data involve some reconciliation of output-based, expenditure-based, and income-based methods. ${ }^{2}$ Even if each of the three sources of information are unbiased and similarly noisy, using the output-based number (or any of the three) as a preliminary will give rise to predictable revisions. An optimal linear estimate of GDP would involve scaling the output-based number by a factor reflecting the signal-to-noise ratio in those data.

We follow others in attempting to distinguish the news and noise views using standard forecast efficiency tests. Under the news view, revisions must be mean zero; under noise, they need not be. Thus, we initially test the hypothesis that

\footnotetext{
${ }^{1}$ For the U.S., see the editors note in Mankiw and Shapiro (1986); for the U.K., Barklem (2000), and for Japan, Economic Research Institute (2000).

2 The UK process is roughly like this hypothetical example. These three bases for GDP measurement and the reconciliation are explained in Reed (2000).
} 
the revisions are unbiased. If $\varepsilon_{t}$ in (1) is correlated with $X_{t}^{p}$ as in the noise case, $X_{t}^{p}$ will predict the subsequent revision, $R(t) \equiv X_{t}^{f}-X_{t}^{p}$. To test this we use the classic Mincer-Zarnowitz (1969) forecast efficiency test, which involves running the regression,

$$
R_{t}=\alpha+\beta X_{t}^{p}+u_{t}
$$

We test the forecast efficiency implication that $\alpha=\beta=0$. One can also augment the set of explanatory variables in the Mincer-Zarnowitz regression with any variable known at time $t$. Forecast rationality implies that all the coefficients should be zero.

Several earlier papers have applied these tests using revisions to money stock and/or output data, typically for the U.S. ${ }^{3}$ Mankiw and Shapiro (1986) find little evidence against the null hypothesis of forecast rationality using a short sample of U.S. GNP data and so characterize the data revision process as incorporating news. Using U.S. consumption data, Croushore and Stark (1999) find that revisions up to 1 year after the initial data release are uncorrelated with the preliminary data, but that subsequent revisions are weakly predictable using preliminary data. Barklem (2000) finds evidence of bias in revisions to various UK preliminary releases, including GDP.

All of this work, including ours, requires one caveat: because data construction methods are constantly being revised, it is unclear whether past predictability is evidence of future predictability. We partially address this problem by considering both a full sample and a more recent 10-year sample and by using pseudo out-ofsample methods. It remains true that methods in most countries have changed considerably, even in the past decade. Considering even shorter samples is problematic because statistical power falls as the sample size shrinks and because very recent data has not had much time to be revised.

\footnotetext{
${ }^{3}$ Mankiw, Runkle and Shapiro (1984), using U.S. money stock data, reject the null hypothesis of forecast rationality. Other authors, including Kavajecz and Collins (1995), also using U.S. money stock data, reject forecast rationality when using seasonally adjusted data, but not when using the unadjusted data. Similar results are obtained for Canadian money stock data by Milbourne and Smith (1989).
} 


\section{Our preliminary and final GDP data}

Our data comprise preliminary estimates of real quarterly GDP growth rates and their subsequent revisions for the G-7 countries. The data come from the OECD's Main Economic Indicators (MEI). To obtain our preliminary estimate of GDP growth for a given quarter, we find the first monthly issue of the (hardcopy) MEI in which GDP is reported for the relevant quarter and we calculate the implied GDP growth rate. ${ }^{4}$ Throughout, the growth rate is defined as the quarter-over-quarter percent change of real seasonally adjusted GDP (not annualized). The final growth rate is taken from the April 1999 CD of MEI. ${ }^{5}$ These data are not truly final in that, for example, base-year and definitional changes continue indefinitely. To insure that our final numbers are at least mature we end the sample for all countries in 1997Q4.

For the United States, United Kingdom, and Canada, preliminary data are available beginning in 1965Q1. For Japan, the starting date is 1970Q1; for Italy and Germany, 1979Q4; and for France, 1987Q4. The German data refer to West Germany until 1994Q4 and to all of Germany in all subsequent quarters. Unfortunately, West German real GDP data are no longer included in MEI, so for Germany the final growth rate is taken from the Haver Analytics Germany database, rather than from the April 1999 MEI CD. As such, the results for Germany should be treated with some caution.

\footnotetext{
${ }^{4}$ Although MEI is published monthly, we are not guaranteed that the first number published in MEI is really the first number ever released. It is advantageous to collect all of our data from a consistent source, such as MEI. Data for a given quarter is usually reported in MEI soon after the end of that quarter (usually within 2 or 3 months). For the United States, our preliminary data for GDP growth is very similar, though not always identical, to that in the Croushore-Stark dataset (Croushore and Stark (1999)). These data, in turn, are obtained from the May, August, November and February issues of the Survey of Current Business, for quarters 1, 2, 3, and 4, respectively.

${ }^{5}$ GNP was in fact reported in the early years of the sample.
} 


\section{Predictability of GDP growth revisions}

\subsection{Bias in Revisions and Other Summary Statistics}

Table 1 reports summary statistics for the preliminary and final rates of seasonallyadjusted quarterly real GDP growth for each of the G-7 countries. The table gives both the results over the longest span of data available for each country (top panel) and for the more recent 10 years, 1988Q1-1997Q4, for all countries (bottom panel).

For all countries the revisions are large, as reflected in the root mean square error. Consistent with these numbers, the final annualized growth rate is more than a percentage point different from the preliminary at least half the time in these data. $^{6}$ Revisions are generally smaller for the shorter, recent sample, but even in this period, the root mean square revision ranges from a low of about one- third of a percentage point for the U.S., Canada, and France, to over three-quarters of a percentage point for Germany, the UK and Japan. ${ }^{7}$ In comparing the magnitudes of data revisions across countries, one should bear in mind that some countries, including the United Kingdom, issue their preliminary data much more quickly than others. ${ }^{8}$

For the full sample, the mean revision to GDP growth is positive for all countries except Japan, indicating a general tendency toward pessimism in initial numbers. The bias is quite large in the UK at over one-quarter percentage point (a full point at an annual rate). We also report a $t$-statistic for testing the forecast efficiency hypothesis that the mean revision is zero. Throughout the paper, all standard errors are heteroskedasticity and autocorrelation robust, using Newey-West standard errors with a lag truncation parameter of $4 .^{9}$ The hypothesis that the mean revision is

\footnotetext{
${ }^{6}$ This share is 0.48 for Canada and over 0.5 for all the other countries.

${ }^{7}$ Our evidence for the UK is roughly consistent with what Barklem (2000) found using somewhat different revision measures.

${ }^{8}$ The Federal Reserve Board has recorded the dates of first announcements on GDP growth over the last 5 years, for the G-7 countries. The average time between the end of the quarter and the first announcement is 56 days across the G-7 as a whole, but is only 26 days for the United Kingdom and 30 days for the United States.

${ }^{9}$ Newey and West, 1987. The results are not sensitive to the choice of this lag truncation parameter: indeed it would make very little difference if it were set to 0 . If we knew that the final
} 
zero is rejected for the U.S., Canada, and the UK. ${ }^{10}$ The fact that the results are only significant for these 3 countries is in part driven by the fact that these are the countries with the longest sample period. The statistically significant bias for the U.S. can also be found in the Croushore-Stark data. ${ }^{11}$

During the 1988-97 sub-period, mean revisions are quite small for all countries but the UK and, given the short sample, one cannot reject the hypothesis that the mean is zero. For the UK the mean revision remains large and statistically significantly different from zero. Bias is, of course, the simplest form of predictability in revision; we now examine the predictability of the data revision process more comprehensively.

\subsection{Forecastable revisions: a preliminary look}

If the preliminary data are an efficient forecast, it is also the case that they should have lower standard deviations than the final data: optimal forecasts are less variable than the item forecasted. In Canada, Germany, Japan, Italy, and the UK, however, the ratio of preliminary to final standard deviations is greater than one. For Japan, Italy and the UK the ratio is above 1.3. Further, if the data revision process only incorporates news, then there should be no systematic relation between the preliminary announcement and the subsequent revision. In fact, one can see a striking negative relationship in the scatter plots of revisions against the preliminary data for several countries, notably Japan, Italy and the UK (Figure 1). For these countries, high preliminary numbers are systematically revised downwards and low

data were released $m+1$ quarters after the preliminary data, then the data revision process would be an $m$-dependent process, as an implication of forecast rationality. However, our construction of the data does not record the timing of the release of the final data (which is in any case never truly final, because of benchmark revisions among other things). Accordingly, in our dataset, forecast rationality carries no specific implications for the autocorrelation of data revisions. This is the reason why we use autocorrelation robust standard errors, while noting that this makes little difference in practice.

${ }^{10}$ Unless otherwise stated, we use the 5 percent level to judge significance and test rejections.

${ }^{11}$ In calculations not shown in this paper, we find that in the Croushore-Stark data, available on the website of the Philadephia Federal Reserve Bank, the revision of output growth going from the first release to the most recently available data is significantly positive, as is the revision going from the first release to the second release (one quarter later). 
preliminary numbers are systematically revised upwards.

This informal evidence against forecast rationality is exactly as one would expect under the noise interpretation of the data revision process. The noise contributes to excessive variance of the preliminary data. Further, unusual observations in the preliminary data tend to be revised toward more normal values as the noise is removed. This informal evidence is confirmed in the next section.

\subsection{The Mincer-Zarnowitz test}

We now turn to the Mincer-Zarnowitz test of forecast rationality-a test of the hypothesis that $\alpha=\beta=0$ in the regression (2). This regression allows us formally to measure the relation seen in Figure 1. For the full sample, the $F$-statistic for testing this hypothesis suggests rejection of forecast rationality for every country except France, which has the shortest sample (Table 2, top panel). As one would predict from Figure 1, overwhelming rejections are obtained for Japan, Italy and the United Kingdom.

The degree of predictability in data revisions varies substantially across countries. The adjusted $R^{2}$ ranges from 2 percent in the United States to 62 percent in Italy.

For the most recent 40 quarter sample (Table 2, bottom panel), the $F$-test again rejects forecast rationality for Italy, Germany and Japan, and for the UK at the 10 percent level, but not for the other countries. The explanatory power of the regression also remains quite large for the four countries where we find predictability.

Overall, we take these Mincer-Zarnowitz results as evidence of strong predictability of GDP revisions in 4 of our countries both in the full and recent samples. For Canada and the U.S., there is weak evidence of predictability in the full sample. In the shorter, recent sample, either the reduced number of observations or, perhaps, improvements in the revision process in these 2 countries leaves little evidence of predictability. We now turn to some robustness checks of and extensions to these basic results. To preview, neither the robustness checks nor the extensions alter 
much the basic conclusions just illustrated.

\subsection{Recursive estimates and outliers}

Since our estimates are based on a sample that includes very recent data, statistical agencies could not have used our results in the past to generate better preliminary announcements. As a simple check of whether statistical agencies could have done better with data available in the past, we construct recursively adjusted preliminary data series. For each quarter, starting in the $20^{\text {th }}$ quarter of the full sample for each country, we ran the Mincer-Zarnowitz regression using only data that was available in that quarter. Next we adjusted the preliminary data for that quarter by adding to it the fitted revision for that quarter implied by the regression. France is excluded from this exercise due to the short sample.

These results require one caveat. In order to run the regressions we needed an assumption about when the final data become available. We assume that our final data are released 4 quarters after the preliminary data, which is not literally true. We report the mean square error of the raw preliminary data and the recursively adjusted preliminary data as forecasts of the final data (Table 3). We also report a Diebold-Mariano (1995) test of the hypothesis that these mean square errors are equal.

For all of the countries, except the United States, the real-time recursivelyadjusted preliminary data has smaller mean square error than the original preliminary data. The reduction in mean square error is large for Germany, Italy, Japan, and the UK and is statistically significant for Japan and the United Kingdom. The fact that the difference is not statistically significant for Germany and Italy may be due to the relatively short samples for Germany and Italy.

Especially in the early years of the sample, many of the preliminary GDP growth rates are quite extreme. This is particularly true for the United Kingdom in the 1970s. ${ }^{12}$ To see if our results are driven by such outliers, we re-ran the regressions

\footnotetext{
${ }^{12}$ For example, the preliminary growth rate for the United Kingdom in 1971Q1 was -4.7 percent (not annualized): this was subsequently revised to -1.2 percent.
} 
in Table 2, deleting all observations for which the preliminary growth rate deviated from the country-mean by more than 3 percentage points. ${ }^{13}$ The results (Table 4) are entirely consistent with the earlier results (Table 2): these outliers are not driving the results.

\section{$5 \quad$ Augmented forecast efficiency regressions}

Forecast rationality requires that the revisions be unforecastable using any data that was known at the time the preliminary data were released. To see if added explanatory variables strengthen the evidence against forecast rationality, we augment the basic regression with seasonal dummies and five variables known at the time that the preliminary data were released: lagged preliminary data, the growth rate of equity prices, a 3-month interest rate, oil price inflation, and a dummy variable for national elections (Canada, Japan, UK, U.S. only). ${ }^{14}$

We include the seasonal dummies and lagged preliminary data to check for additional simple forms of dynamics in the original specification. We follow Mankiw and Shapiro (1986) in using equity prices and short-term interest rates as business cycle indicators. We add oil prices for the same reason. These business cycle variables may have predictive power if the systematic inefficiencies in the data construction process are affected by the state of the business cycle.

Nordhaus (1975) suggested that incumbent governments might attempt to boost the economy before elections to enhance election prospects. Of course, incumbents might prefer to artificially boost the economic data, rather than actually stimulating the economy. This would avoid some of the efficiency costs of deviating from (otherwise) optimal policy, and after data revisions the evidence would disappear from the historical record. There have been accusations in the press of this sort of

\footnotetext{
13 There were 9 such outliers in the United Kingdom, 3 in Japan, 2 each in Germany, Italy and the United States, 1 in Canada and none in France. All but 2 of these outliers occurred prior to 1987.

${ }^{14}$ Equity prices are measured by the stock price indices for each country reported in MEI. The 3 -month interest rate for each country is also taken from MEI. The oil price is the spot West Texas intermediate crude price.
} 
manipulation in Japan (New York Times, 2000).

We create an election dummy variable that is one if the preliminary number is the last one announced before a national election and zero otherwise. We include this dummy variable only for Canada, Japan, the United Kingdom and the United States because for the other countries there were not enough elections within our sample period to obtain meaningful results. ${ }^{15}$ For the 4 countries with enough elections, we construct the dummy variable by obtaining the exact dates of elections and of the preceding initial GDP announcements from various national newspapers. ${ }^{16}$ If the data for the election quarters are optimistic, then we expect revisions for these quarters to be systematically more negative than at other times.

We emphasize at the outset that there are two reasons other than political manipulation that the election dummy could be significant. First, the prospective election could lead to breaks in economic behavior that are not captured by the methods used in constructing preliminary GDP. For example, suppose that businesses delay marginal investments around the time of elections to wait for the resolution of electoral uncertainty. Methods for estimating a preliminary investment number that do not reflect this break in behavior would lead to optimistic investment estimates. Second, since election timing is endogenous in each country except the U.S., the election dummy could also come in if data-construction biases are correlated with the same variables driving election timing. For example, elections might be called when the economy is robust and the GDP construction methods might be most optimistic at those times. We partially control for this by including our business cycle variables, but these controls are obviously imperfect.

\footnotetext{
${ }^{15}$ Within our sample period there were 8 elections in the United States, 9 in the United Kingdom, 10 in Canada and 16 in Japan, but only 3 in France and 5 each in Germany and Italy (although governments collapse notoriously frequently in Italy, these collapses often do not lead to fresh elections). We are grateful to Deepak Mishra for providing us with some election data.

${ }^{16}$ In the United States, the elections we refer to are presidential elections (midterm elections were disregarded). For Canada, Japan and the United Kingdom, they are all national parliamentary elections (in either house, in the case of Japan).
} 


\subsection{Results for the augmented regressions}

When we include all the additional regressors (Table 5), forecast rationality is rejected for all 7 countries (as opposed to the 6 rejections reported in Table 2). A number of the added regressors are statistically significant for multiple countries, and each regressor is statistically significant, at least at the 10 percent level, for at least one country. For the UK and France, oil price inflation is significant; for the UK and Japan, the interest rate is significant; for Japan and the U.S., equity price growth is significant at the 10 percent level.

Only in the case of France, however, is there an appreciable increase in explanatory power of the regression as measured by the adjusted $R^{2}$. For France the increase is 0.2 ; the next largest increase is the U.S. at 0.06 . Thus, the vast majority of the predictive power comes from the constant and lagged preliminary number.

We also ran the regressions in Tables 5 using only the subsample of data from 1988Q1 on, but omitting the election dummy (because there are too few elections in this subsample). Further, we ran these regressions deleting outliers (as defined

in the construction of Table 4). The results were similar to those in Tables 5, however, and are not shown so as to conserve space. Last, we used the regressions in Table 5 to construct a recursively adjusted preliminary data series (as defined in the construction of Table 3), and found that this has smaller mean square error than that of the raw preliminary data. This reduction in mean square error is statistically significant for Japan and the United Kingdom. These results are omitted to save space but are available from the authors.

\section{$5.2 \quad$ Elections}

For Japan alone, the election dummy is marginally significant (significant at the 10 percent level). The estimated election effect is large, as the final GDP growth rate announced before an election is subsequently revised downwards by about 0.3 percentage points more than for other quarters (thus, the revision is over a full percentage point greater at an annualized rate). 
Because elections are quite seasonal in many countries - most notably the U.S. where they all fall in the $4^{\text {th }}$ quarter-we are concerned with possible collinearity between the election dummy variable and the seasonal dummy variables. ${ }^{17}$ For example, in the U.S. none of the seasonal dummy variables enters significantly, but their presence could make it difficult to detect an independent election effect. More generally, a joint test of the hypothesis that the seasonal dummies are zero fails to reject for every country but France and the UK (Table 5, final row).

Thus, in Table 6 , we report the regression from Table 5 with the quarterly dummy variables removed. Very few coefficients change greatly in value or in signficance. As for the election dummy, removing the quarterly dummies does not affect the conclusion that the election dummy is insignificant in Canada, the UK, or the U.S. For Japan, the magnitude of the election effect remains largely unchanged and the election effect is now significant at the 5 percent level.

As we emphasized above, there is no presumption that the marginally significant effect in Japan is due to political manipulation. We found some evidence that this effect is most prominent in the investment component of GDP, suggesting that it could be due to the sort of time-shifting of investment around elections discussed above. ${ }^{18}$ It should also be noted that there are considerably more elections in our Japanese sample than in any other country. Thus, our tests have much more power to detect an electoral effect.

\footnotetext{
17 In Canada, there were 1, 3, 2 and 4 elections in quarters 1-4, respectively. In the United Kingdom, there were 2, 6, 0 and 1 elections, and in Japan, there were 1, 3, 7 and 5 elections, in quarters 1-4, respectively.

18 We re-ran the regression in Table 5, replacing the preliminary and revised output growth data by the analogous investment growth data (private fixed investment), collected from the same sources. The coefficient on the election dummy was significantly negative in this regression. We also ran these regressions for consumption, government spending, export and import growth data, but the coefficients on the election dummy were not significant at any conventional significance level in any of these regressions.
} 


\section{Conclusions}

Revisions to GDP announcements are quite large in all the G-7 countries. The magnitude has fallen some in recent years, but remains large. In Canada, the UK, and the U.S., the preliminary announcements have been significantly pessimistic. In several countries - the UK, Italy, Japan - the revisions are highly predictable. In these countries, about half the variability of revisions can be accounted for by data available at the time of the preliminary announcement. For the other countries, there is some evidence of predictability, but the measured degree of predictability is rather modest. Thus, for these countries it seems that revisions primarily reflect news not available at the time of the preliminary announcement.

When we do find predictability of revisions, it is mostly due to the predictive power of the preliminary number: extreme values, large or small, in the preliminary growth rate tend to be revised toward the mean. This is exactly what one would expect under the noise view of revisions in which revsions remove measurement error from earlier announcements.

This paper has potentially important implications for macroeconometric work. Several recent papers have pointed out the problems with using fully revised data; such work rests on the assumption that agents perfectly anticipate revisions. A corrective that has been used is to re-do the work using preliminary data. Of course, this may rest on the assumption that revisions are completely unpredictable. This assumption is a reasonable approximation for the U.S., but for Italy, Japan, and the UK, revisions are quite predictable and neither extreme assumption is appropriate. Analysts should probably use some sort of recursively adjusted data, such as those constructed here. 


\section{References}

Barklem, A. (2000): Revisions Analysis of Initial Estimates of Key Economic Indicators and GDP Components, Economic Trends, No. 556, pp.31-52.

Croushore, D. and T. Stark (1999): A Real-Time Dataset for Macroeconomists, Journal of Econometrics, forthcoming.

De Jong, P. (1987): Rational Economic Data Revisions, Journal of Business and Economic Statistics, 5, pp.539-548.

Diebold, F.X. and R.S. Mariano (1995): Comparing Predictive Accuracy, Journal of Business and Economic Statistics, 13, pp.253-263.

Diebold, F.X. and G. Rudebusch (1991): Forecasting Output with the Composite Leading Index: A Real-Time Analysis, Journal of the American Statistical Association, 86, pp.603-610.

Economic Research Institute (2000): The Recent Opinions on Japan's GDP Figures and Our Approach, Economic Planning Institute, mimeo (June 9).

Evans, C.L. (1998): Real-Time Taylor Rules and the Federal Funds Futures Market, Federal Reserve Bank of Chicago Economic Perspectives, 22, pp.44-55.

Howrey, E.P. (1978): The Use of Preliminary Data in Econometric Forecasting, Review of Economics and Statistics, 60, pp.193-200.

Howrey, E.P. (1984): Data Revision, Reconstruction and Prediction: An Application to Inventory Investment, Review of Economics and Statistics, 66, pp.386393.

Kavajecz, K. and S. Collins (1995): Rationality of Preliminary Money Stock Estimates, Review of Economics and Statistics, 77, pp.32-41.

Mankiw, N.G., D.E. Runkle and M.D. Shapiro (1984): Are Preliminary Announcements of the Money Stock Rational Forecasts?, Journal of Monetary Economics, 14, pp.15-27.

Mankiw, N.G. and M.D. Shapiro (1986): News or Noise: An Analysis of GNP Revisions, Survey of Current Business, May 1986, pp.20-25.

Mariano, R.S. and H. Tanizaki (1995): Prediction of Final Data with Use of Preliminary and/or Revised Data, Journal of Forecasting, 14, pp.351-380.

Milbourne, R.D. and G.W. Smith (1989): How Informative are Preliminary Announcements of the Money Stock in Canada?, Canadian Journal of Economics, 22, pp.595-606.

Mincer, J. and V. Zarnowitz (1969): The Evaluation of Economic Forecasts in J. Mincer (ed.), Economic Forecasts and Expectations, NBER, New York. 
New York Times (2000): Japan Assailed for Omitting Data in Growth Calculations, May 24, p. C1.

Newey, W.K. and K.D. West (1987): A Simple Positive Semidefinite, Heteroskedasticity and Autocorrelation Consistent Covariance Matrix, Econometrica, 55, pp703-708.

Nordhaus, W. (1975): The Political Business Cycle, Review of Economic Studies 42, pp.169-190.

Orphanides, A. (1998): Monetary Policy Rules Based on Real-Time Data, Board of Governors of the Federal Reserve System, Finance and Economics Discussion Paper, forthcoming American Economic Review.

Orphanides, A. (2000): The Quest for Prosperity Without Inflation, European Central Bank Working Paper.

Robertson, J.C. and E.W. Tallman (1998): Data Vintages and Measuring Forecast Model Performance, Federal Reserve Bank of Atlanta, Working Paper.

Reed, G. (2000): How the Preliminary Estimate of GDP is Produced, Economic Trends, No. 556, pp.53-61. 
Table 1: Summary of announcements and revisions for two samples

\begin{tabular}{llllllll}
\hline \hline & Canada & France & Germany & Italy & Japan & UK & US \\
\hline Revision & \multicolumn{7}{c}{ start-1997Q4 } \\
$\quad$ Mean & 0.18 & 0.01 & 0.11 & 0.11 & -0.07 & 0.3 & 0.1 \\
$\quad$ t-stat & 2.97 & 0.11 & 1.36 & 1.45 & -1.02 & 4.53 & 2.57 \\
$\quad$ root mean square & 0.81 & 0.36 & 0.97 & 0.85 & 0.83 & 1.14 & 0.53 \\
$\quad$ mean absolute & 0.58 & 0.28 & 0.69 & 0.59 & 0.64 & 0.84 & 0.4 \\
final mean growth & 0.86 & 0.49 & 0.48 & 0.48 & 0.91 & 0.57 & 0.76 \\
prelim mean growth & 0.69 & 0.48 & 0.37 & 0.37 & 0.98 & 0.27 & 0.65 \\
& & & & & & & \\
Revision & & & $1988 \mathrm{Q} 1-1997 \mathrm{Q} 4$ & & & \\
$\quad$ Mean & 0.01 & -0.02 & 0.2 & -0.01 & 0.05 & 0.22 & 0.02 \\
t-stat & 0.21 & -0.28 & 1.61 & -0.19 & 0.61 & 2.08 & 0.41 \\
root mean square & 0.34 & 0.34 & 1.08 & 0.52 & 0.8 & 0.73 & 0.33 \\
$\quad$ mean absolute & 0.26 & 0.27 & 0.74 & 0.36 & 0.63 & 0.4 & 0.26 \\
final mean growth & 0.53 & 0.47 & 0.57 & 0.41 & 0.66 & 0.52 & 0.62 \\
prelim mean growth & 0.52 & 0.49 & 0.37 & 0.42 & 0.61 & 0.3 & 0.6 \\
& & & & & & & \\
\hline \hline
\end{tabular}

Notes: The final and preliminary number are both quarter-over-quarter growth rates in percent. The revision is final minus preliminary. The $t$-statistics are based on autocorrelation and heteroskedasticity consistent standard errors and are for the hypothesis that the mean is zero. The sample ends in 1997Q4 for all countries. The full sample begins in 65Q1, 87Q4, 79Q4, 79Q4, 70Q1,65Q1,65Q1, for the seven countries, respectively. The results for Germany are tentative, because different databases were used to calculate preliminary and final growth rates. 
Table 2: Mincer-Zarnowitz Regression in two samples

\begin{tabular}{llllllll}
\hline \hline & Canada & France & Germany & Italy & Japan & UK & US \\
\hline \multirow{7}{*}{ constant } & 0.44 & 0.12 & 0.28 & 0.34 & 0.33 & 0.44 & 0.17 \\
& 4.94 & 1.32 & 2.9 & 4.88 & 4.25 & 6.11 & 2.28 \\
prelim & -0.39 & -0.24 & -0.48 & -0.64 & -0.41 & -0.52 & -0.1 \\
& -4.8 & -1.78 & -4.29 & -6.54 & -7.18 & -8.55 & -1.16 \\
F & 26.7 & 3.3 & 18.7 & 49.4 & 57.4 & 83.3 & 7.6 \\
p-val & 0 & 0.2 & 0 & 0 & 0 & 0 & 0.02 \\
$\bar{R}^{2}$ & 0.27 & 0.07 & 0.4 & 0.62 & 0.42 & 0.52 & 0.02 \\
& & & & & & \\
& & & $1988 \mathrm{Q} 1-1997 \mathrm{Q} 4$ & & & \\
constant & 0.06 & 0.1 & 0.42 & 0.17 & 0.28 & 0.41 & 0.09 \\
& 1.01 & 1.15 & 2.81 & 1.65 & 2.4 & 2.18 & 0.82 \\
prelim & -0.09 & -0.23 & -0.61 & -0.44 & -0.38 & -0.65 & -0.12 \\
& -1.24 & -1.71 & -4.18 & -2.62 & -3.59 & -2.24 & -1.01 \\
F & 1.8 & 3 & 18.6 & 7.3 & 12.9 & 5.2 & 1.1 \\
p-val & 0.41 & 0.23 & 0 & 0.03 & 0 & 0.07 & 0.57 \\
$\bar{R}^{2}$ & 0 & 0.08 & 0.56 & 0.28 & 0.32 & 0.46 & 0 \\
& & & & & & & \\
\hline \hline
\end{tabular}

Notes: See the notes to Table 1. In each specification the dependent variable is the revision in percent; all independent variables are listed in column 1 . The number in smaller type under the coefficient estimate is a $t$-statistic for the hypothesis that the coefficient is zero. The row labelled $\mathrm{F}$ is an $\mathrm{F}$ test of the hypothesis that all coefficients are zero; the p-value for this test is given in the next row. 
Table 3: MSE of preliminary data and adjusted preliminary data as forecasts of

\begin{tabular}{lllllll}
\multicolumn{7}{c}{ final data } \\
\hline \hline & Canada & Germany & Italy & Japan & UK & US \\
MSE (Raw) & 0.6413 & 1.1641 & 0.338 & 0.5879 & 1.2973 & 0.2877 \\
MSE (Adjusted) & 0.4656 & 0.7389 & 0.2321 & 0.3816 & 0.6203 & 0.3091 \\
Diebold-Mariano & 1.14 & 1.55 & 1.03 & 2.31 & 2.62 & -1.56 \\
& & & & & \\
\hline \hline
\end{tabular}

Notes: This table shows the mean square error of the raw preliminary data and of the recursively adjusted preliminary data (adjusted using the Mincer-Zarnowitz regression, as discussed in the text). The Diebold-Mariano statistic measures the significance of the difference between the MSE (Raw) and MSE (Adjusted). It is asymptotically normally distributed.

Table 4: Mincer-Zarnowitz regression, full sample, observations with extreme preliminary growth rates deleted

\begin{tabular}{llllllll}
\hline \hline & Canada & France & Germany & Italy & Japan & UK & US \\
\hline \multirow{2}{*}{ constant } & 0.35 & 0.12 & 0.21 & 0.34 & 0.44 & 0.43 & 0.09 \\
& 4.47 & 1.32 & 2.71 & 4.41 & 5.28 & 5.48 & 2.23 \\
prelim & -0.28 & -0.24 & -0.35 & -0.7 & -0.5 & -0.55 & -0.01 \\
& -4.51 & -1.78 & -5.13 & -7.35 & -7.79 & -7.14 & -0.24 \\
F & 22.7 & 3.3 & 27.5 & 55.5 & 62.7 & 53.7 & 7 \\
p-val & 0 & 0.2 & 0 & 0 & 0 & 0 & 0.03 \\
$\bar{R}^{2}$ & 0.14 & 0.07 & 0.24 & 0.62 & 0.43 & 0.45 & -0.01 \\
& & & & & & & \\
\hline \hline
\end{tabular}

Notes: see the notes to Table 2. The Table reports the same results as Table 2, except that observations with outlier preliminary data (as defined in the text) are deleted. 
Table 5: Forecast Efficiency Regression, full sample

\begin{tabular}{llllllll}
\hline \hline & Canada & France & Germany & Italy & Japan & UK & US \\
\hline \multirow{2}{*}{ constant } & 0.51 & 0.51 & 0.08 & -0.16 & 0.86 & 0.53 & 0.10 \\
& 2.59 & 1.79 & 0.18 & -0.29 & 3.42 & 2.67 & 0.51 \\
prelim & -0.46 & -0.12 & -0.45 & -0.71 & -0.44 & -0.51 & -0.08 \\
& -6.27 & -1.70 & -3.68 & -8.91 & -7.48 & -9.08 & -0.94 \\
prelim(-1) & 0.17 & 0.30 & 0.08 & 0.06 & 0.02 & 0.04 & -0.05 \\
& 2.31 & 4.21 & 1.41 & 1.81 & 0.40 & 0.67 & -0.85 \\
q1 & -0.11 & -0.12 & -0.32 & -0.01 & -0.10 & 0.54 & 0.20 \\
& -0.68 & 1.01 & -1.03 & -0.12 & -0.49 & 2.73 & 1.49 \\
q2 & 0.12 & -0.14 & -0.20 & 0.09 & 0.11 & 0.50 & 0.10 \\
& 0.78 & -1.45 & -1.21 & 0.55 & 0.73 & 2.73 & 0.79 \\
q3 & -0.18 & -0.26 & -0.29 & -0.10 & 0.04 & 0.42 & -0.13 \\
& -1.09 & -3.17 & -1.61 & -0.71 & 0.30 & 2.78 & -0.88 \\
oil & 0.35 & -2.01 & -2.19 & 0.28 & -0.27 & -2.66 & -0.34 \\
& 0.38 & -2.68 & -1.51 & 0.36 & -0.27 & -2.85 & -0.62 \\
stock ret & 0.01 & -0.27 & 0.24 & 0.34 & -0.42 & 0.00 & 0.01 \\
& 0.80 & -1.45 & 0.86 & 1.24 & -1.82 & 0.40 & 1.72 \\
interest & -0.01 & -0.03 & 0.03 & 0.02 & -0.07 & -0.05 & 0.00 \\
& -1.15 & -1.66 & 0.64 & 0.66 & -2.08 & -2.36 & 0.29 \\
election & -0.08 & & & & -0.27 & 0.01 & -0.13 \\
& -0.37 & & & & -1.71 & 0.02 & -0.90 \\
F & 76.1 & 119.5 & 44.6 & 154.2 & 100.0 & 507.2 & 28.9 \\
p-val & 0.00 & 0.00 & 0.00 & 0.00 & 0.00 & 0.00 & 0.00 \\
$\bar{R}^{2}$ & 0.32 & 0.27 & 0.39 & 0.65 & 0.45 & 0.59 & 0.08 \\
\multirow{2}{*}{$F^{*}$ (seas) } & 5.70 & 10.73 & 4.01 & 3.25 & 1.14 & 11.43 & 7.05 \\
p-val & 0.13 & 0.01 & 0.26 & 0.36 & 0.77 & 0.01 & 0.07 \\
\hline \hline & & & & & & & \\
\hline
\end{tabular}

Notes: See the notes to Table 2. The row labelled $F^{*}$ (seas) is for a joint test of the joint hypothesis that the 3 seasonal dummy variables are zero in the regression in the top panel. 
Table 6: Forecast Efficiency Regression without Quarterly Dummies, full sample

\begin{tabular}{llllllll}
\hline \hline & Canada & France & Germany & Italy & Japan & UK & US \\
\hline \multirow{3}{*}{ constant } & 0.47 & 0.43 & -0.12 & -0.19 & 0.88 & 0.92 & 0.13 \\
& 2.86 & 1.48 & -0.29 & -0.33 & 3.82 & 4.86 & 0.82 \\
prelim & -0.47 & -0.18 & -0.46 & -0.71 & -0.46 & -0.54 & -0.10 \\
& -6.18 & -2.24 & -4.01 & -8.70 & -7.91 & -8.84 & -1.05 \\
prelim(-1) & 0.18 & 0.33 & 0.09 & 0.07 & 0.03 & 0.04 & -0.04 \\
& 2.41 & 5.57 & 1.55 & 2.20 & 0.59 & 0.68 & -0.66 \\
oil & 0.21 & -2.00 & -1.98 & 0.35 & -0.27 & -2.69 & -0.37 \\
& 0.21 & -2.72 & -1.52 & 0.43 & -0.26 & -3.25 & -0.59 \\
stock ret & 0.01 & -0.29 & 0.25 & 0.34 & -0.42 & 0.01 & 0.02 \\
& 0.64 & -1.57 & 0.91 & 1.22 & -1.88 & 1.16 & 2.06 \\
interest & -0.01 & -0.03 & 0.03 & 0.02 & -0.07 & -0.05 & 0.00 \\
& -1.14 & -1.68 & 0.62 & 0.69 & -2.14 & -2.42 & 0.26 \\
election & 0.01 & & & & -0.32 & -0.17 & -0.01 \\
& 0.06 & & & & -2.15 & -0.79 & -0.04 \\
F & 69.4 & 53.1 & 39.3 & 122.2 & 99.3 & 248.8 & 18.5 \\
p-val & 0.00 & 0.00 & 0.00 & 0.00 & 0.00 & 0.00 & 0.01 \\
$\bar{R}^{2}$ & 0.32 & 0.26 & 0.40 & 0.66 & 0.45 & 0.56 & 0.03 \\
& & & & & & & \\
\hline \hline
\end{tabular}

Notes: see the notes to Table 2. 
